\title{
Epidemiology of road traffic crashes in Ilam Province, Iran, 2009-2013
}

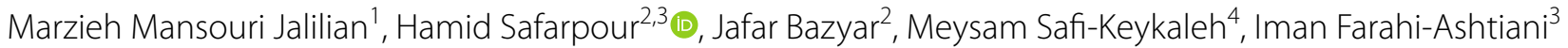 \\ and Ali Khorshidi ${ }^{*}$
}

\begin{abstract}
Objective: Road traffic crashes (RTCs) are major public health challenges of world health systems, and the main leading cause of death in children and young adults aged 5 to 29 years. This study aimed to assess the epidemiology of RTCs in llam, Iran.

Results: The total mortality rate due to RTCs has been increasing every year. There was a statistically significant relationship between age/sex and death or injury from RTCs in pedestrians, drivers, and passengers $(p<0.05)$. There was a significant relationship between the part of body trauma and RTCs in pedestrians $(p<0.001)$. Furthermore, a significant relationship was found between the type of vehicle and using seat belt with RTCs in drivers and passengers $(p=0.000)$.
\end{abstract}

Keywords: Road safety, Road traffic injury, Risk factors, Vehicle, Accident, Trauma

\section{Introduction}

Road traffic crashes (RTCs) are the principal public health problem in developed and developing countries [1-3]. RTCs are defined as fatal or non-fatal injuries incurred as a result of a road traffic crash [4]. Death from RTCs affect not only victims, but also families and the wider community at the national level with physical, psychological, economic, and quality of life consequences [5]. Approximately, 1.35 million people die each year as a result of RTCs [6]. More than $90 \%$ of deaths occur in low and middle-income countries [7]. They are the main leading cause of death for children and young adults aged 5 to 29 years [6]. The causes of road crashes can be attributed to human, vehicular, and environmental factors. Besides the environmental factors, Geographical conditions and climate change can increase the number of RTCs [8]. Moreover, Temperature, rainfall, sandstorms, and number of vehicles are responsible for RTCs [9].

\footnotetext{
*Correspondence: khorshidi-a@medilam.ac.ir

${ }^{5}$ Department of Epidemiology, School of Medicine, Ilam University

of Medical Sciences, Ilam, Iran

Full list of author information is available at the end of the article
}

Iran has one of the highest mortality rates from RTCs among middle-income countries [10,11], which are the leading cause of early death and years of life lost (YLL), and the most common cause of injuries [12, 13]. Approximately, 0.8 million people (1.1\% of Iran's population) are hospitalized per year due to RTCs, which imposes a significant burden on the country's health system. Also, more than one-third of hospital beds are allocated to RTCs victims [14]. In a study conducted between 2004 and 2011, the average rate of deaths from RTCs was 31 per 100,000 population [15]. Also, according to the WHO report in 2015, the mortality rate caused by RTCs in Iran was 32 deaths per 100,000 persons [12].

In Ilam province of Iran, due to the climatic and geographical conditions, RTCs result in major life and financial losses annually [16]. The rate of death due to RTCs in Ilam province in 2012 was estimated to $24 / 82$ per 100,000 people. Furthermore, as an strategic location, this province is exposed to high road traffic for about 30 days every year in Arbaeen mass gathering [17, 18]. At this time, travel to the border is by road and personal vehicles, which increases the risk of RTCs [17]. Therefore, 
prevention of these injuries is necessary and prevention clearly requires recognition and attention to the pattern of risk factors. Knowing the intervention with more impact on RTCs mortality prevention by authorities may result in better planning to prevent the consequences of these types of events in the province at a lower cost and higher efficiency. Due to the lack of comprehensive studies on the epidemiology of RTCs in Ilam province, this study aimed to assess the epidemiology of RTCs in Ilam, Iran.

\section{Main text Methods}

This was a retrospective cross-sectional study. Data on RTCs in Ilam were gathered during a five-years period (2009-2013) using census method. The data were collected from COM114 police form filled by road safety experts at the accident scene. This form contains a relatively large number of variables that are used by the police in all traffic accidents. Data are collected in two parts of general and specific information. In the general section, information about time, place, road conditions, weather conditions, lighting conditions, vehicle characteristics, characteristics of people (driver, pedestrian and passenger) and causes of the crashes are collected. In the specific section, information related to crash maps and expert advice are collected and entered in the traffic crashes database. The tool questions are designed to be open and closed. The data is entered into the system by the police in different parts of the country and it is possible for users to process and report it at the local and national levels. Permission was obtained from Ilam University of Medical Sciences and approved by the ethical committee. The aims of the study were explained to the police office. Then, for the retrieval of individual records and confidentiality of information, written consent was given to the record office of the police. The collected information was about the environmental conditions of injuries, human factors, and vehicle characteristics as well as the consequences of RTCs. Data in the police database is maintained in four separate sections and stored in the Microsoft Excel ${ }^{\circledR}$. The data of each section were reviewed separately and controlled and modified in terms of human errors (redundancy, typos errors, etc.) as necessary. To use all the data related to a specific crash, the data of these four sections were linked through common keywords. The method of controlling missing data was to add them to the categories that had the highest frequency. The missed data were considered as variables that have a more frequent rate than others. Data were entered into the SPSS-20 software and examined in three categories of pedestrians, drivers, and passengers. In each category, the relationship of the dependent variable (injury or death due to RTCs) with independent variables using Chi-square test, as well as the incidence rate of death or injury in terms of sex and age during the studied years were analyzed.

\section{Results}

During the five-year period, the crude mortality rate has been increasing every year from 22.06 in 2009 to 43.23 in 2013 , per 100,000 population. The mean age-standardized incidence rate was 23.03 per 100,000 population. The rate of death from RTCs in passengers increased every year from 5 in 2009 to 22 in 2013 per 100,000 population.

There was a statistically significant relationship between age and death or injury from RTCs in all the three categories of pedestrians, drivers and passengers $(\mathrm{P}<0.05)$. The number of deaths in males in all the three categories of pedestrians $(40,2.8 \%)$, passengers $(299$, $8.9 \%)$, and drivers $(462,2.2 \%)$ was more than those of females. There was a significant relationship between sex and death or injury from RTCs in pedestrians, passengers and drivers $(\mathrm{P}<0.05)$. In all the categories, the deaths and injuries in males were more than those of females. Most pedestrians $(708,80 \%)$ had an educational level under a high school diploma, and none of the pedestrians with academic education died. There was a significant relationship between education level and death or injury from a RTCs in drivers and passengers $(P<0.05)$. The people with Non-Academic education had the highest rate of death or injury.

There was a significant relationship between employment type and death or injury from RTCs in drivers. Employed drivers had higher rate of deaths or injuries compared to unemployed drivers $(\mathrm{P}=0.05)$. However, there was no statistically significant relationship between employment type and death or injury in pedestrians and passengers (Table 1). A significant relationship was found between the type of vehicle and the RTCs in drivers $(\mathrm{P}<0.001)$. Most drivers $(78.3 \%)$ who had an accident with a small vehicle were injured, and $69(0.3 \%)$ of the drivers who had an accident with a motorcycle have died.

There was a statistically significant relationship between using seat belts and death or injury from RTCs in drivers and passengers $(\mathrm{P}<0.001)$. Most drivers $(3819$, $65.7 \%)$ who used seat belts were injured and $122(1.2 \%)$ who had not used seat belts died. A total of 123 (11\%) of passengers that did not fasten their seat belts died. There was a significant relationship between the type of motor vehicle and death or injury in drivers and passengers $(P=0.000)$. Light vehicle drivers have more deaths and injuries compared to heavy vehicles and motorcycles (Table 2).

Part of body trauma had a statistically significant relationship with death or injury from RTCs in pedestrians 
Table 1 Frequency distribution of RTCs in pedestrians, passengers and drivers by demographic characteristics

\begin{tabular}{|c|c|c|c|c|c|c|c|c|c|}
\hline \multirow[t]{2}{*}{ Variable } & \multicolumn{3}{|l|}{ Pedestrian } & \multicolumn{3}{|l|}{ Driver } & \multicolumn{3}{|l|}{ Passenger } \\
\hline & Injured & Died & Total & Injured & Died & Total & Injured & Died & Total \\
\hline \multicolumn{10}{|l|}{ Age(year) } \\
\hline $20<$ & $376(26.9 \%)$ & $15(1.1 \%)$ & $391(28 \%)$ & 1208 (6.1\%) & $34(2 \%)$ & 1242 (6.3\%) & $517(21.6 \%)$ & $84(3.5 \%)$ & $601(25.1 \%)$ \\
\hline $21-40$ & 469 (33.5\%) & $6(4 \%)$ & 475 (34\%) & $13,430(67.9 \%)$ & $264(1.3 \%)$ & $13,694(69.3 \%)$ & 1148 (47.9\%) & $148(6.2 \%)$ & $1296(54.1 \%)$ \\
\hline $41-60$ & 302 (21.6\%) & $14(1 \%)$ & $316(22.6 \%)$ & 4407 (22.3\%) & $112(6 \%)$ & 4519 (22.9\%) & $343(14.3 \%)$ & $72(3 \%)$ & 415 (17.3\%) \\
\hline$>60$ & $206(14.7 \%)$ & $10(7 \%)$ & $216(15.5 \%)$ & 307 (1.6\%) & $7(0 \%)$ & $314(1.6 \%)$ & $70(2.9 \%)$ & $14(6 \%)$ & $84(3.5 \%)$ \\
\hline Total & 1353 (96.8\%) & $45(3.2 \%)$ & 1398 (100\%) & 19,352 (97.9\%) & $417(2.1 \%)$ & 19,769 (100\%) & $2078(86.7 \%)$ & $318(13.3 \%)$ & $2396(100 \%)$ \\
\hline P value & 0.02 & & & 0.05 & & & 0.01 & & \\
\hline \multicolumn{10}{|l|}{ Sex } \\
\hline Female & $521(36.1 \%)$ & $9(0.6 \%)$ & 530 (36.7\%) & $504(2.3 \%)$ & $2(0 \%)$ & $506(2.4 \%)$ & 1209 (35.9\%) & 158 (4.7\%) & 1367 (40.6\%) \\
\hline Male & $873(60.5 \%)$ & $40(2.8 \%)$ & $913(63.3 \%)$ & $20,511(95.5 \%)$ & $462(2.2 \%)$ & $20,973(97.6 \%)$ & 1700 (50.5\%) & 299 (8.9\%) & 1999 (59.4\%) \\
\hline Total & 1394 (96.6\%) & $49(3.4 \%)$ & $1443(10 \%)$ & $21,015(98.7 \% 0$ & $464(2.2 \%)$ & $21,479(10 \%)$ & 2909 (86.4\%) & $457(13.6 \%)$ & $3366(100 \%)$ \\
\hline P value & 0.007 & & & 0.006 & & & 0.005 & & \\
\hline \multicolumn{10}{|l|}{ Educational level } \\
\hline Illiterate & $129(14.6 \%)$ & $7(8 \%)$ & $136(15.4 \%)$ & $441(4 \%)$ & $9(1 \%)$ & $450(4.1 \%)$ & 142 (6.9\%) & $26(1.3 \%)$ & 168 (8.1\%) \\
\hline Non-Academic & 708 (80\%) & $22(2.5 \%)$ & 730 (82.5\%) & 9187 (83.1\%) & $150(1.4 \%)$ & 9337 (84.4\%) & $1642(79.4 \%)$ & $208(10.1 \%)$ & 1850 (89.5\%) \\
\hline Academic & $19(2.1 \%)$ & $0(0 \%)$ & $19(2.1 \%)$ & 1267 (11.5\%) & $8(1 \%)$ & 1275 (11.5\%) & $39(1.9 \%)$ & $10(5 \%)$ & $49(2.4 \%)$ \\
\hline Total & $856(96.7 \%)$ & $29(3.3 . \%)$ & 885 (100\%) & 10,895 (98.5\%) & $167(1.5 \%)$ & 11,062 (100\%) & $1823(88.2 \%)$ & $244(11.8 \%)$ & 2067 (100\%) \\
\hline PValue & 0.31 & & & 0.01 & & & 0.04 & & \\
\hline \multicolumn{10}{|l|}{ Employment type } \\
\hline Unemployed & $153(28.8 \%)$ & $2(0.4 \%)$ & 155 (29.1\%) & 2290 (18.2\%) & $18(1 \%)$ & $2308(18.4 \%)$ & 161 (33.4\%) & $15(3.1 \%)$ & $176(36.5 \%)$ \\
\hline Employed & 371 (69.7\%) & $6(1.1 \%)$ & 377 (70.9\%) & 10,115 (80.6\%) & $129(1 \%)$ & $10,244(81.6 \%)$ & $291(60.4 \%)$ & $15(3.1 \%)$ & 306 (63.6\%) \\
\hline Total & $524(98.5 \%)$ & $8(1.5 \%)$ & $532(100 \%)$ & 12,405 (98.8\%) & $147(1.2 \%)$ & 12,552 (100\%) & 452 (93.8\%) & $30(6.2 \%)$ & $482(100 \%)$ \\
\hline P Value & 0.79 & & & 0.05 & & & 0.11 & & \\
\hline
\end{tabular}

Table 2 Type of crash by type of vehicle, and seatbelt by driver and passenger

\begin{tabular}{|c|c|c|c|c|c|c|}
\hline \multirow[t]{2}{*}{ Variable } & \multicolumn{3}{|l|}{ Driver } & \multicolumn{3}{|l|}{ Passenger } \\
\hline & Injured & Died & Total & Injured & Died & Total \\
\hline \multicolumn{7}{|l|}{ Motor vehicle } \\
\hline Heavy & 2395 (11.1\%) & $132(0.6 \%)$ & 2527 (11.7\%) & $128(3.8 \%)$ & $114(3.4 \%)$ & $242(7.2 \%)$ \\
\hline Light & $16813(78.3 \%)$ & $266(1.2 \%)$ & 17079 (79.5\%) & $2402(71.4 \%)$ & $310(9.2 \%)$ & $2712(80.7 \%)$ \\
\hline Motorcycle & 1806 (8.4\%) & $69(0.3 \%)$ & 1875 (8.7\%) & $375(11.2 \%)$ & $33(1 \%)$ & $408(12.1 \%)$ \\
\hline Total & 21014 (97.8\%) & $467(2.2 \%)$ & 21481 (100\%) & 2905 (86.4\%) & 457 (13.6\%) & $3362(100 \%)$ \\
\hline P value & 0.000 & & & 0.000 & & \\
\hline \multicolumn{7}{|l|}{ Seat belt } \\
\hline Used & 3819 (65.9\%) & $133(2.3 \%)$ & 3952 (68\%) & 297 (26.5\%) & $19(1.7 \%)$ & $316(28.2 \%)$ \\
\hline Not used & $1740(29.9 \%)$ & $122(2.1 \%)$ & $1862(32 \%)$ & $680(60.8 \%)$ & $123(11 \%)$ & $803(71.8 \%)$ \\
\hline Total & $5559(95.6 \%)$ & $255(4.4 \%)$ & $5814(100 \%)$ & 977 (87.3\%) & 142 (12.7\%) & $1119(100 \%)$ \\
\hline P value & 0.000 & & & 0.000 & & \\
\hline
\end{tabular}

$(\mathrm{P}<0.001)$, while there was no such relationship in passengers. Most pedestrians $(37,80 \%)$ and passengers (1977, 76.66\%) were injured in the head and face, and none of the pedestrians who were injured in the lower extremities died. (Table 3).

\section{Discussion}

In this study, the rate of death from RTCs in the province of Ilam has been increasing, which might be due to the higher number of vehicles and more exposure of people. This rate (43.23) was higher than the mean rate in 
Table 3 Part of body trauma and RTCs in pedestrian and passenger

\begin{tabular}{|c|c|c|c|c|c|c|}
\hline \multirow[t]{2}{*}{ Variable } & \multicolumn{3}{|l|}{ Pedestrian } & \multicolumn{3}{|l|}{ Passenger } \\
\hline & Injured & Died & Total & Injured & Died & Total \\
\hline \multicolumn{7}{|l|}{ Part of body } \\
\hline Head and face & $375(80 \%)$ & $4(1 \%)$ & $379(81 \%)$ & 1977 (76.6\%) & 327 (12.6\%) & 2304 (89.26\%) \\
\hline Upper limbs & $56(12 \%)$ & $5(1 \%)$ & $61(13 \%)$ & $175(6.78 \%)$ & $13(0.005 \%)$ & 188 (7.28\%) \\
\hline Lower limbs & $29(6 \%)$ & $0(0 \%)$ & $29(6 \%)$ & $82(3.17 \%)$ & 7 (0.002\%) & $89(3.44 \%)$ \\
\hline Total & 460 (98\%) & $9(2 \%)$ & 469 (100\%) & 2234 (86.55\%) & 347 (13.44\%) & $2581(100 \%)$ \\
\hline$P$ value & 0.000 & & & 0.22 & & \\
\hline
\end{tabular}

the Eastern Mediterranean region (32.2) [19]. It was also higher than the Iran mean rate of 31 per 100,000 population in a study by Bahadory Monfared et al. in Iran [15], and far more than the rate of 33.4 per 100,000 population in a study by Entezami et al. in northern provinces of Iran. It might be due to the specific climatic and geographical conditions of the province of Ilam [20]. However, it was lower than 52.9 per 100,000 population in a study by Hasani et al. in Semnan, Iran [21].

The results showed a significant relationship between age and death or injury from RTCs. Some studies show that there was no significant relationship between age and death or injury, which was not consistent with this study $[22,23]$. However, other studies show that age has a significant relationship with death or injury from RTCs $[11,24]$. Elderly pedestrians had a greater risk of death compared to younger individuals [25]. It may be a result of other confounding risk factors for pedestrian injury outcome rather than a positive relationship between pedestrian age and severity of the outcome [26].

In this study, a significant relationship was found between sex and death or injury from RTCs. The results of some studies conducted in the field of RTCs and their epidemiology of injury or death showed that sex had the greatest effect on placing people in the injury or death groups, which was consistent with this study [11, 12, 24, $25,27,28]$. However, a study that assessed "the influence of age on the morbidity and mortality of pedestrian victims" showed that there was no relationship between sex and injury severity or death [26]. International studies reveal that the male-to-female ratio of fatal RTCs worldwide is 2.7:1 [29], which was lower than the one observed in the study 5.6/1 [30]. This gender difference can be attributed to the increased susceptibility and exposure of men due to specific occupational, cultural, and social issues [12]. Also, it is maybe due to more exposure and more dangerous behaviors of males in contrast to the more cautious behaviors of females during driving [28].

A significant relationship was found between education level and death or injury from RTCs in drivers and passengers. Most pedestrians had an educational level under a high school diploma, and none of the pedestrians with had academic education died. The results of the present study were similar to the results of previous studies $[23,30-32]$. One study shows that one-fifth of the deaths from road traffic crashes occurred among illiterate people and people with university-level education have the lowest proportion [30]. A significant effect of education level status on traffic accident death tolls was observed $[31,32]$, and with higher education level, the injury incidence reduced [23]. This result is partially explained as drivers with higher educational level have better economic and cultural status enabling them to own more expensive and standard vehicles as well as more respect to the driving regulations [12].

In this study, no relationship was found between the employment type of drivers and death or injury from RTCs. Moreover, there was no statistically significant relationship between employment type and death or injury in pedestrians and passengers. In a study of the relationship between injury and socioeconomic status, the results showed no significant relationship between employment type and injury from road crashes [23].

There was a significant relationship between the type of motor vehicle and death or injury in drivers and passengers $(\mathrm{P}=0.000)$. A study on RTCs' consequences from different types of road user showed that motorcyclists and pedestrians suffer the most severe injuries and more complicated medical problems [33]. Based on the findings of a study, due to force or the sharp parts of vehicles, RTCs with a specially equipped vehicle such as oversize loaded trucks is more injurious than other vehicle types including trucks, buses and sedans [33].

The results indicated that the use of seat belts had a significant relationship with traffic crashes leading to death or injury, and findings from previous studies confirmed this [34, 35]. The use of seat belts is compulsory in Iran, but most people do not use this safety tool [36]. It reduces the damage by preventing the occupants from colliding with the interior of the vehicle or being thrown 
out of the vehicle [37]. Although seat belt has been proven to decrease the severity of injury as well as mortality, it is also associated with specific injury patterns [38]. Trauma to the head and face was the most common cause of death in pedestrians and passengers in this study. Many studies show that the most common cause of injury or death from RTCs was a strike in the head, which was consistent with this study $[24,25,28,36,39,40]$.

\section{Conclusion}

It appears that policies and educational programs for young and middle-aged groups will contribute to reducing deaths from RTCs. Also, requiring passengers to comply with driving regulations and fastening seat belts appear to be necessary to prevent and minimize death from road traffic crashes. Reducing mortalities due to RTCs should be the top priority for the government and health-care system. A multistage approach to injuryrelated problems and death and the focus on the groups who need priority intervention are necessary to reduce the incidence of injury and death from RTCs.

\section{Limitations}

This study was limited to the data collected from the COM 114 form, which were incomplete because they were not collected for research purposes.

\section{Abbreviation}

RTCs: Road Traffic Crashes.

\section{Acknowledgements}

We would like to thank all those people who have helped in the writing of this study.

\section{Authors' contributions}

MMJ, and AK designed the study. AK, JB, and HS analyzed the data. MMJ, HS, IFA, and MSK drafted the manuscript. All authors read and approved the final manuscript.

\section{Funding}

No funding to declare.

\section{Availability of data and materials}

All data obtained during this study is included in this article. The datasets used and/or analysed during the current study are available from the corresponding author on reasonable request.

\section{Ethics approval and consent to participate}

Permission was obtained from Ilam University of Medical Sciences and approved by the ethical committee. The aims of the study were explained to the police office. Then, for the retrieval of individual records and confidentiality of information, written consent was given to the record office of the police.

\section{Competing interests}

The authors have declared that no competing interests exist.

\section{Author details}

${ }^{1}$ Psychosocial Injuries Research Center, Ilam University of Medical Sciences, Ilam, Iran. ${ }^{2}$ Department of Nursing, Faculty of Nursing and Midwifery, Ilam University of Medical Sciences, Ilam, Iran. ${ }^{3}$ Department of Health in Disasters and Emergencies, School of Public Health and Safety, Shahid Beheshti
University of Medical Sciences, Tehran, Iran. ${ }^{4}$ Malayer School of Nursing, Hamadan University of Medical Sciences, Hamadan, Iran. ${ }^{5}$ Department of Epidemiology, School of Medicine, Ilam University of Medical Sciences, Ilam, Iran.

Received: 2 September 2020 Accepted: 28 October 2020

Published online: 10 November 2020

\section{References}

1. Soori H, Khorasani-Zavareh D. Road traffic injuries measures in the Eastern Mediterranean Region: findings from the Global Status Report on Road Safety-2015. J Inj Violence Res. 2019;11(2):149-58.

2. Khodadadizadeh A, Jahangiri K, Khorasani-Zavareh D, Vazirinejad R. Epidemiology of vehicle fire fatalities of road traffic injuries in kerman Province, Iran: a cross-sectional study. Open Access Macedonian J Medical Sci. 2019;7(12):2036-43.

3. Eftekhari A, Dehghani Tafti A, Khorasani-Zavareh D, Nasiriani K, Hajimaghsoudi $\mathrm{M}$, Falahzadeh $\mathrm{H}$. Root causes of preventable prehospital deaths in road traffic injuries: a systematic review. Trauma Monthly. 2019;24(4):1-8.

4. Peden M, Oyegbite K, Ozanne-Smith J, Hyder AA, Branche C, Rahman A, et al. World report on child injury prevention: World Health Organization Geneva; 2009.

5. Ramadani N, Zhjegi V, Berisha M, Hoxha R, Begolli I, Salihu D, et al. Public health profile of road traffic accidents in Kosovo 2010-2015. Open Access Macedonian J Med Sci. 2017;5(7):1036-41.

6. World Health Organization. Global status report on road safety 2018 2018. https://www.who.int/violence_injury_prevention/road_safet y_status/2018/en/.

7. Hyder AA. Injuries in low-and middle-income countries: a neglected disease in global public health. Injury. 2013;44(5):579-80.

8. Jones AP, Haynes R, Kennedy V, Harvey I, Jewell T, Lea D. Geographical variations in mortality and morbidity from road traffic accidents in England and Wales. Health Place. 2008;14(3):519-35.

9. Islam M, Alharthi M, Alam M. The impacts of climate change on road traffic accidents in Saudi Arabia. Climate. 2019;7(9):103.

10. Khorasani-Zavareh D, Mohammadi R, Khankeh HR, Laflamme L, Bikmoradi A, Haglund BJ. The requirements and challenges in preventing of road traffic injury in Iran A qualitative study. BMC Public Health. 2009;9(1):486.

11. Roshanfekr P, Afzali Ardakani H, Sajjadi H, Khodaei-Ardakani MR. Social differences in the prevalence of road traffic injuries among pedestrians, and vehicle and motorcycle users in Iran: Results of a national multiple indicator demographic and health survey (IrMIDHS, 2010). Int J Preventive Med. 2019;10(1):98.

12. Shahbazi F, Soori H, Khodakarim S, Ghadirzadeh M, Nazari S. Analysis of mortality rate of road traffic accidents and its trend in 11 years in Iran. Arch. Trauma Res. 2019;8(1):17-22.

13. Soori H, Royanian M, Zali A, Movahedinejad A. Study of changes on Road Traffic Injury Rates, before and after of Four Interventions by Iran Traffic Police. Pejouhandeh J. 2009;14(1):15-20 (Persian).

14. Ebrahimipour H, Khani M, Salehabadi S, Babaei Heidarabadi A, Molavi Taleghani Y, Mirzaie N,etal Demographically Investigate the Trauma Resulting From Road Traffic Accidents in Injured Patients Referred to Taleghani Hospital in Mashhad (Khorasan razavi, Iran)-2013. Saf Promot Inj Prev. 2014;2(3):155-60 (Persian).

15. Bahadorimonfared A, Soori H, Mehrabi Y, Delpisheh A, Esmaili A, Salehi $M$, et al. Trends of fatal road traffic injuries in Iran (2004-2011). PLoS ONE. 2013:8(5):65-98.

16. Jalilian MM, Safarpour H, Bazyar J, Keykaleh MS, Malekyan L, Khorshidi A Environmental related risk factors to road traffic accidents in Ilam. Iran Med Arch. 2019;73(3):169-72.

17. Karampourian A, Ghomian Z, Khorasani-Zavareh D. Qualitative study of health system preparedness for traumatic incidents in a religious mass gathering. Injury. 2019;50(5):1097-104.

18. Mozafari A, Shafiei E, Jamshibeigi Y, Sahebi A. Lessons Learned From Trauma Injuries in Arbaeen 2019 in Ilam Province, Iran. Int J Med Toxicol Forensic Med. 2020;10(2):28614.

19. World Health Organization. Eastern Mediterranean status report on road safety: call for action 2010. https://apps.who.int/iris/handle/10665/11990 8. 
20. Entezami N, Soori H, Khosravi A, Ghadirzadeh M. Epidemiology of fatal road traffic accidents in Northern provinces of Iran during 2009 to 2010. Journal of safety promotion and injury prevention. 2015;3(1):1-8 (Persian).

21. Hasani J, Hashemi Nazari SS, Gadirzadeh M, Shojaei A. An epidemiological study of fatal road traffic accidents in Semnan province (Iran) in 2011. J Semnan unevercitylof Med Sci. 2016;17(2):304-11.

22. Khosravi Shadmani F, Soori H, Zayeri F, Eini E, Mehmandar M. Effect of Some Person and Vehicle Related Factors on Offenses Status of Road Traffic Injuries in Iran. Journal of Transportation Engineering. 2011;3(2):11724 (Persian).

23. Kim S-K, Kim H, Lee K, Kang H-T, Oh S-S, Ko SB. The relationship between injury and socioeconomic status in reference to the fourth Korean National Health and Nutrition Examination Survey. Annals Occup Environ Med. 2014;26(1):1.

24. Abedi L, Khorasani-Zavareh D, Sadeghi-Bazargani H. Epidemiological pattern of motorcycle injuries with focus on riding purpose: Experience from a middle-income country. J Anal Res Clin Med. 2015:3(3):149-59.

25. Kim S-C, Lee H-J, Kim J-M, Kong S-Y, Park J-S, Jeon H-J, et al. Comparison of epidemiology and injury profile between vulnerable road users and motor vehicle occupants in road traffic fatalities. Traffic Injury Prevention. 2019;20(6):581-7.

26. Henary BY, Ivarsson J, Crandall JR. The influence of age on the morbidity and mortality of pedestrian victims. Traffic injury prevention. 2006;7(2):182-90.

27. Bakhtiyari M, Soori H. Epidemiology of traffic crashes outcomes and related factors. Safty promotion and injury prevention. 2013;1(3):50-159 (Persian).

28. Manouchehrifar M, Ghalandari R, Hatamabadi $\mathrm{H}$. The impact of safety equipment on traffic accidents: a hospital based study. Trauma Monthly. 2019:24(1):1-5.

29. Mohan D. Traffic safety and city structure: lessons for the future. salud pública de méxico. 2008;50(S1):93-100

30. Khorasani-Zavareh D, Haglund BJ, Mohammadi R, Naghavi M, Laflamme L. Traffic injury deaths in West Azarbaijan province of Iran: a cross-sectional interview-based study on victims' characteristics and prehospital care. Int J Injury Control Safety Promotion. 2009;16(3):119-26.

31. Oralhan B, Göktolga ZG. Determination of the risk factors that influence occurrence time of traffic accidents with survival analysis. Iranian J Public Health. 2018;47(8):1181.

32. Wang $X, Y u H$, Nie $C$, Zhou $Y$, Wang $H$, Shi $X$. Road traffic injuries in China from 2007 to 2016: the epidemiological characteristics, trends and influencing factors. PeerJ. 2019;7:e7423.

33. Chung Y, Song T-J, Yoon B-J. Injury severity in delivery-motorcycle to vehicle crashes in the Seoul metropolitan area. Accid Anal Prev. 2014;62:79-86.

34. Pakgohar A, Khalili M, Saffarzade M. The Consideration of Human Factor's Role in Occurrence and Aggravation of Road Accidents Based on the Regression Models LR and CART. Traffic Management Studies. 2009;4(13):49-66 (Persian).

35. Rezazadeh J, Alavinia SM, Kavyani A, Jabari S, Ganji R. Factors contributing to driver's condition after fatal and injury vehicle accidents in North Khorasan province- New Year 2012. Journal of Safety promotion and injury prevention. 2013;1(1):19-25 (Persian).

36. Montazeri A. Road-traffic-related mortality in Iran: a descriptive study. Public Health. 2004;118(2):110-3.

37. Abbas AK, Hefny AF, Abu-Zidan FM. Seatbelts and road traffic collision injuries. World J Emergency Surg. 2011;6(1):18.

38. Afifi I, El-Menyar A, Al-Thani H, Peralta R. Seatbelt versus seatbelt and airbag injuries in a single motor vehicle crash. Int J Crit IIIn Inj Sci. 2015;5(1):46-9.

39. T.TSH-NSGMT. Epidemiology of fatal traffic injuries in the Sistan and Baluchistan province in 2011. Saf Promot Inj Prev. 2015;3(3):161-8.

40. Abedini Z, Tavanania M. Epidemiological Study of Road Traffic Accidents in Qom. Qom Univ Med Sci J. 2011;5(2):90-5 (Persian).

\section{Publisher's Note}

Springer Nature remains neutral with regard to jurisdictional claims in published maps and institutional affiliations.
Ready to submit your research? Choose BMC and benefit from:

- fast, convenient online submission

- thorough peer review by experienced researchers in your field

- rapid publication on acceptance

- support for research data, including large and complex data types

- gold Open Access which fosters wider collaboration and increased citations

- maximum visibility for your research: over $100 \mathrm{M}$ website views per year

At BMC, research is always in progress.

Learn more biomedcentral.com/submissions 